\title{
Organically-Expanded Graphite/Octadecylamine: Structural, Thermal and Relaxation Evaluation*
}

\author{
Lilian G. Carreira $^{1 \#}$, Luis C. Mendes ${ }^{1}$, Maria R. G. Ribeiro ${ }^{2}$, Pedro J. Sebastião ${ }^{2}$ \\ ${ }^{1}$ Instituto de Macromoléculas Professora Eloisa Mano (IMA), Universidade Federal do Rio de Janeiro (UFRJ), Rio de Janeiro, Brasil; \\ ${ }^{2}$ Instituto Superior Técnico (IST), Universidade Técnica de Lisboa (UTL), Lisboa, Portugal. \\ Email: "1lgasparelli@ima.ufrj.br
}

Received March $12^{\text {th }}, 2013$; revised April 17 ${ }^{\text {th }}, 2013$; accepted April 28 $8^{\text {th }}, 2013$

Copyright (C) 2013 Lilian G. Carreira et al. This is an open access article distributed under the Creative Commons Attribution License, which permits unrestricted use, distribution, and reproduction in any medium, provided the original work is properly cited.

\begin{abstract}
Natural graphite was chemically modified by an acid mixture $\left(\mathrm{H}_{2} \mathrm{SO}_{4} / \mathrm{HNO}_{3}, 4: 1\right)$ using sonication. The resulting material was then expanded with octadecylamine by the dispersion method. The sample was characterized by scanning electron microscopy (SEM), Fourier transform infrared spectroscopy (FT-IR), thermogravimetry (TG), wide-angle X-ray diffraction (WAXD) and relaxometry-low-field nuclear magnetic resonance (LFNMR). The SEM images revealed the expansion of the graphite layers. The presence of $\mathrm{CH}$ absorption was detected in the infrared spectrum of the expanded sample. The WAXD showed an additional diffraction peak at lower $2 \theta$ angle, indicating that intercalation of octadecylamine was successful. The thermogravimetry curve revealed three degradation steps. Two of them could be attributed to different structures (delaminated and exfoliated). The relaxometry showed that the relaxation time was dependent on the frequency and the curve of the graphite/octadecylamine presented two peaks-approximately before $10^{6} \mathrm{~Hz}$ and after $10^{7} \mathrm{~Hz}$. The results permitted inferring that organically modified graphite was achieved.
\end{abstract}

Keywords: Graphite; Acid Oxidation; Octadecylamine; Sonication

\section{Introduction}

Due to the intrinsic properties, many synthetic and natural fillers, both modified and unmodified, are employed alone or in micro and nanocomposites. Silica is one of the most used. Hybrid materials containing different amounts of Aerosil ${ }^{\circledR}$ were studied by Tavares et al. [1] to investigate relationship among silica content, molecular structure and intermolecular interactions. Sol-gel silica was synthesized through hydrolysis and condensation of tetraethyl orthosilicate (TEOS) for use in dental composites [2]. Different biopolymer/filler systems were investigated and changes in the relaxation times were detected by proton-spin lattice relaxation [3]. Relaxometry study showed the influence of Viscogel ${ }^{\mathbb{B}} \mathrm{B} 8$ and silica on relaxation times in poly (lactic acid) nanocomposites [4]. Lamellar $\alpha$-zirconium phosphate was expanded with octadecylamine and incorporated in linear low density polyethylene (LLDPE) to produce nanocomposites [5]. Alphazirconium phosphate was synthesized by refluxing and added to poly (vinyl alcohol) to obtain nanocomposites

\footnotetext{
"Special description of the title.

"Corresponding author.
}

[6]. Novel fire retardant material using $\alpha$-zirconium phosphate was prepared [7]. An organic-inorganic hybrid layered zirconium phenylphosphate was prepared and used in a nanocomposite based on poly (ethylene terephthalate) [8].

Graphite is an abundant natural material. Its good electrical conductivity, thermal, chemical and mechanical properties attract research interest in it [9]. Hwang and collaborators [10] prepared supports for PtRu catalysts in direct methanol fuel cells using modified graphite carbon nanofibers. Electrocatalysts were produced by carbon nanotubes and graphite powder [11]. Electrode material for a vanadium redox flow battery was prepared by graphite felt with nanodispersed bismuth [12]. Selective determination of dopamine was performed through functionalizated-graphene modified graphite [13]. A graphite-epoxy composite was prepared for electrochemical immunosensing [14]. Expanded graphite was applied in the preparation of a nanocomposite based on styrene-butadiene rubber [15]. A graphite electrode modified by 8-hydroxiquinolines was used for determination of copper at trace levels [16]. An electrodeposited Pb-modified graphite strip electrode was developed as a trichloro- 
ethylene sensor [17].

In this work, organically-expanded graphite with octadecylamine was produced for use in extrinsically conducting polymer. Structural, thermal and relaxation evaluation are reported.

\section{Experimental}

\subsection{Materials}

Graphite powder was supplied by Nacional de Grafite Ltda. The oxidizing agent - sufuric acid $(98 \%)$ and nitric acid $(65 \%)$-were supplied by Vetec. Octadecylamine was supplied by Spectrum.

\subsection{Graphite Treatment}

Natural graphite (NG) was modified in two steps. The first step was based on literature reports [18-20]. To remove the moisture before treatment, the graphite powder was dried at $80^{\circ} \mathrm{C}$ for 12 hours. A sulphonitric solution (sulfuric and nitric acid mixture, 4:1 $\mathrm{v} / \mathrm{v}$ ) was added to the graphite powder. The suspension was sonicated and stirred at room temperature for 5 hours. In this process, the graphite acid mixture (AM-G) was obtained. After that, the suspended powder was filtered and washed with deionized water until $\mathrm{pH} 5.5$ and dried at $80^{\circ} \mathrm{C}$ for 12 hours.

The second step consisted of octadecylamine (ODA) functionalization. AM-G was added in a 70/30 v/v alcohol solution and the suspension was maintained without stirring for 24 hours. After that, the suspension was stirring for 24 hours and then filtered and washed with ethanol for removal of non-reacted octadecylamine and dried at $80^{\circ} \mathrm{C}$ for 12 hours to obtain ODA-AM-G.

\subsection{Thermal Analysis}

The thermogravimetric analysis was performed with a TGA 92 SETARAM under air atmosphere operating in the range of $30^{\circ} \mathrm{C}-700^{\circ} \mathrm{C}$ at a heating rate of $10^{\circ} \mathrm{C} / \mathrm{min}$.

\subsection{Morphological and Structural Evaluation}

Scanning electron microscopy (SEM) was performed with a JEOL JSM $5610 \mathrm{LV}$ microscope with $15 \mathrm{kV}$ of voltage, with magnification up to 3000 times.

Wide-angle x-ray diffraction (WAXD) was carried out in a Brüker D8 Advance diffractometer, using $\mathrm{CuK} \alpha$ radiation with $40 \mathrm{KV}$ of voltage and current of $40 \mathrm{~mA}$, with $2 \theta$ between $2^{\circ}-35^{\circ}$.

FTIR spectroscopy was performed with a Thermo Nicolet Nexus Instrument. The samples were analyzed in a medium infrared region (4000 - $600 \mathrm{~cm}^{-1}$ ) using attenuated total reflectance (ATR) and using $\mathrm{KBr}$ disks, with resolution of $2 \mathrm{~cm}^{-1}$ and 640 scans.

\subsection{Low-Field Nuclear Magnetic Resonance Relaxometry}

The measurements of proton spin lattice relaxation time $\left(\mathrm{T}_{1} \mathrm{H}\right)$ in NG is not possible due this material have only carbon atoms in its composition. Thus, the acid mixture (AM) was analyzed as the starting point for comparison with the treated materials. So, the measurements of proton spin lattice relaxation time $(\mathrm{T} 1 \mathrm{H})$ in $\mathrm{AM}, \mathrm{AM}-\mathrm{G}$ and ODA-AM-G were carried in the frequency range between $50 \mathrm{kHz}$ and $300 \mathrm{MHz}$ using different techniques. The measurements of $\mathrm{T}_{1}$ above $9 \mathrm{MHz}(23 \mathrm{MHz}, 90$ $\mathrm{MHz}$ and $300 \mathrm{MHz}$ ) were performed in two different devices with inversion-recovery pulse sequence $\left(180^{\circ}\right.$ $\tau-90^{\circ}$ ). The variation range of the waiting interval ( $\tau$ between the pulses ranged of 0.1 to $10,000 \mathrm{~ms}$ and the interval between recycle applied to the end of the pulse sequence was 5 seconds. The devices were a Maran Ultra 23 and a $0.21-7.1 \mathrm{~T}$ variable magnetic field NMR spectrometer.

In turn, the measurements of $\mathrm{T}_{1}$ in the range of $50 \mathrm{KHz}$ until $9 \mathrm{MHz}$ were done at room temperature using a fast field cycling (FFC) device developed at the physics department of Instituto Superior Técnico, Portugal. In this type of relaxometry, the analyses were proceeded through the sequence of field cycles. In each cycle, the sample remained subjected to the $\mathrm{B}_{\mathrm{E}}$ field during a time $\tau$. After the $B_{E} \rightarrow B_{D}$ transition, a pulse of radiofrequency was applied to the sample in resonance with the Lamor detection frequency. The free induction decay was detected and the sample was left to relax to equilibrium for a stabilization time at a $T_{1}$ value five times longer. The cycle time was always greater than the stabilization time. The initial amplitude of the free induction decay signal was proportional to the magnetization $M_{z}(\tau)$. The $M_{z}(\tau)$ decay can in general be multi-exponential, with different relaxation times. All measurements were done according to the work developed by Sousa and collaborators [21] and Preto and collaborators [22].

\section{Results}

The results provided by SEM, FT-IR, WAXD, TG and LFNMR are discussed hereafter.

\subsection{SEM Results}

Figure 1 shows the SEM images (magnification-3000x) of the NG, AM-G and ODA-AM-G. In comparison with $\mathrm{NG}$, morphological changes can be seen in the AM-G image, evidencing partial lamellar expansion. The image the sample modified with octadecylamine (ODA-AM-G) indicated that partial lamellar exfoliation was successful. This permits inferring that the insertion of the hydroxyl $(\mathrm{OH})$ and carboxyl groups $(\mathrm{COOH})$ on the surfaces of the 


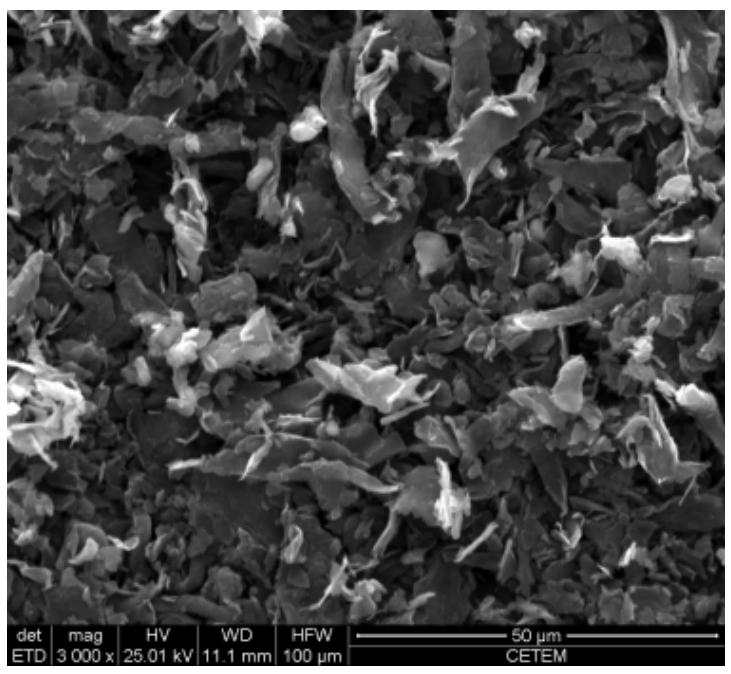

(a)

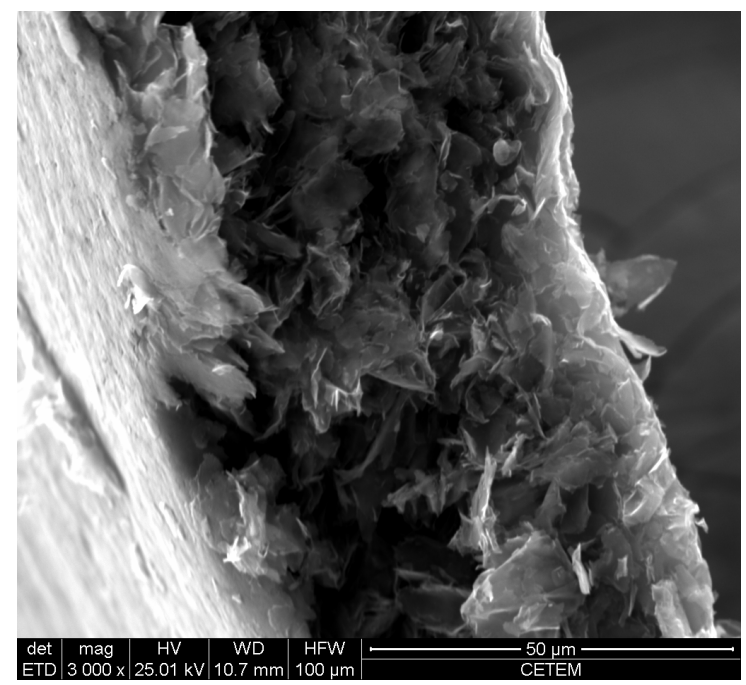

(b)

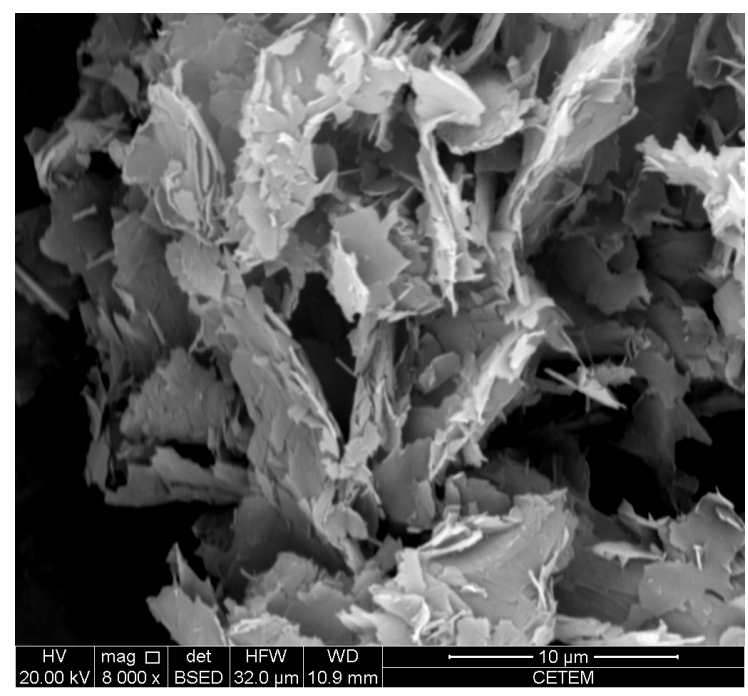

(c)

Figure 1. SEM images for NG (a), AM-G (b) and ODA-AMG (c) samples. graphite layers and their distension was promoted by acid oxidation and sonication. The presence of $\mathrm{OH}$ and $\mathrm{COOH}$ groups enabled the modified graphite to react with octa decylamine and to expand and exfoliate its layers.

\subsection{FTIR Results}

The FTIR spectra of the samples are shown in Figures 2(a) and (b). As expected, the NG spectrum did not present any absorption in the medium infrared range. In the AM-G (Figure 2(b)) spectrum, OH $\left(3500 \mathrm{~cm}^{-1}\right)$ and $\mathrm{COOH}\left(1700 \mathrm{~cm}^{-1}\right)$ could be detected. The bands at 3333 , 3252 and $3161 \mathrm{~cm}^{-1}$ (amine $\mathrm{N}-\mathrm{H}$ bonds) and in the range of $2918-1366 \mathrm{~cm}^{-1}$-related to the C-H and N-H bonds - are characteristic of octadecylamine (Figure 2(a)). The ODA-AM-G spectrum showed absorptions related to ODA, indicating the insertion of amine in the graphite galleries, obtaining modified graphite.

\subsection{WAXD Results}

Figure 3 shows the WAXD results. The NG and AM-G

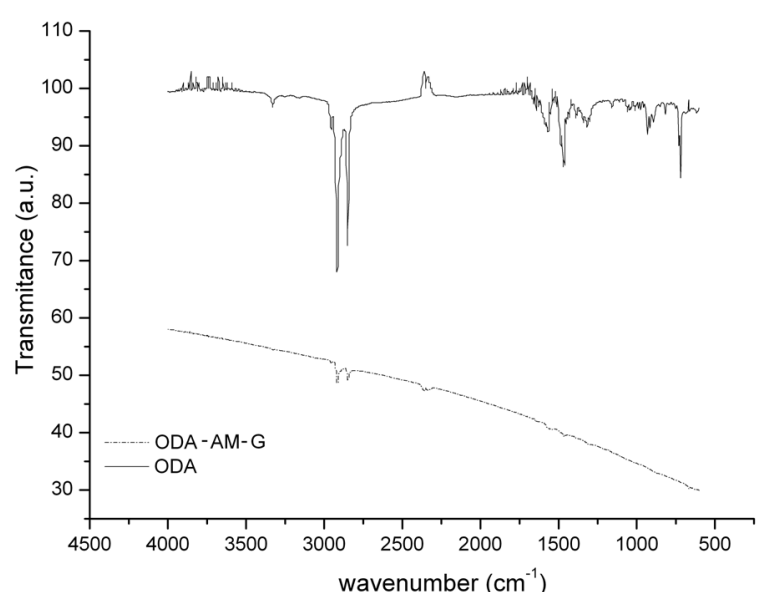

(a)

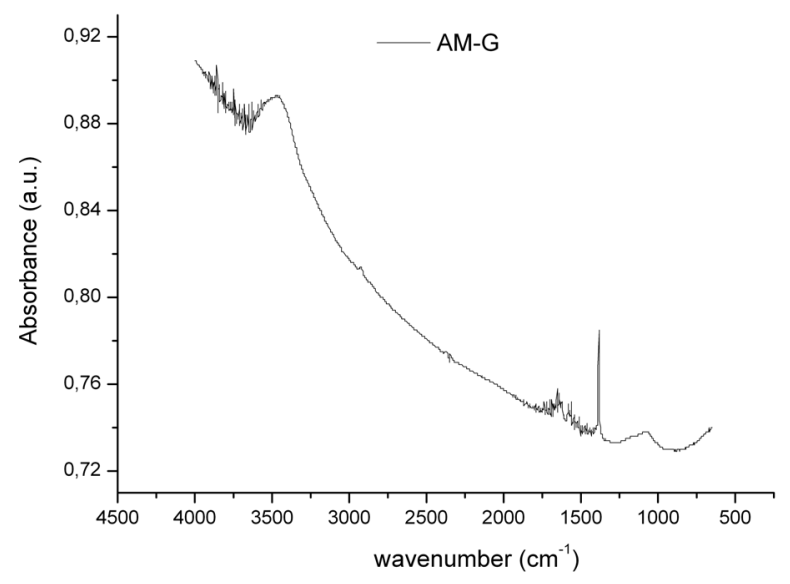

(b)

Figure 2. (a) FTIR spectra for ODA-AM-G and ODA samples; (b) FTIR spectra for AM-G sample. 
diffractrograms presented a single $2 \theta$ peak at $26.5^{\circ}$ but the diffractogram of the treated graphite showed a broadened and less intense diffraction peak. After acid treatment and sonication processes, the insertion of the $\mathrm{OH}$ and $\mathrm{COOH}$ reactive groups promoted some defects in the crystal distortion and orientation of the graphite lamellar stacking. In the diffractrogram of the graphite modified with octadecylamine (ODA-AM-G), although the $2 \theta$ peak at $26.5^{\circ}$ still remained, it was less intense than for the AM-G and a new diffraction peak around $21^{\circ}$ was observed. This suggests that ODA insertion occurred and at least a partial delaminated structure was achieved. If any exfoliated structure was produced, it could not be detected by WAXD.

\subsection{TGA Results}

Figure 4 shows the thermogravimetric curves. The degradation curve of NG showed a first degradation around $100^{\circ} \mathrm{C}$, attributed water absorption and degradation of the carbon chain around $700^{\circ} \mathrm{C}$. The AM-G curve also re-

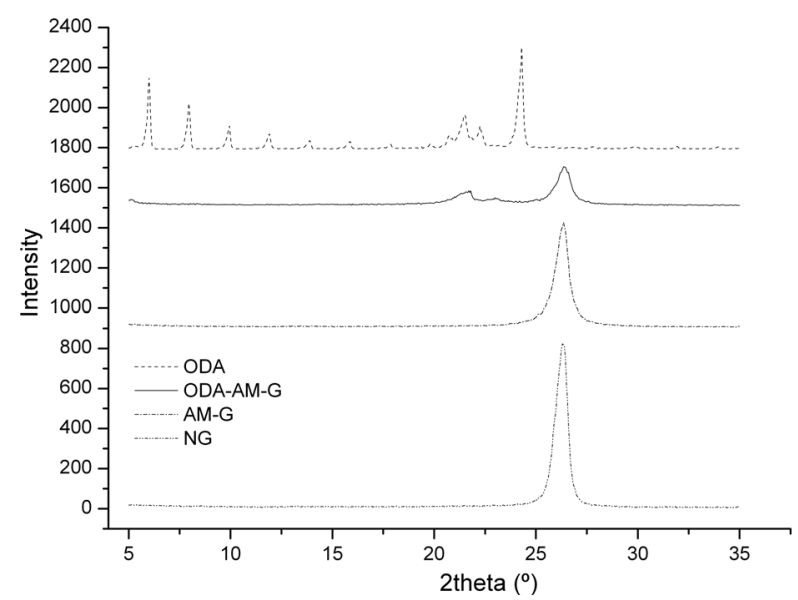

Figure 3. WAXD results for NG, AM-G, ODA-AM-G and ODA samples.

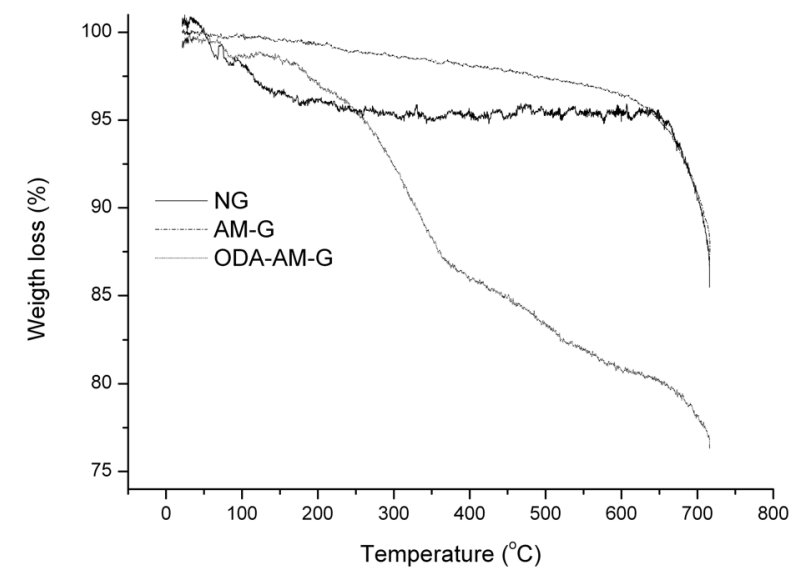

Figure 4. TGA curves for NG, AM-G and ODA-AM-G curves. vealed carbon chain degradation near $700^{\circ} \mathrm{C}$. Three different degradation steps were observed in the ODA-AM$\mathrm{G}$ curve. The first was located between $200^{\circ} \mathrm{C}-350^{\circ} \mathrm{C}$, the second was around $350^{\circ} \mathrm{C}-600^{\circ} \mathrm{C}$ and the final onewas above $700^{\circ} \mathrm{C}$. The first two could be attributed to the degradation of the octadecylamine inserted in different types of structures of the modified graphite (delaminated and exfoliated). The final step represented the degradation of the graphite carbon chain. The results confirmed that organically modified graphite was produced.

\subsection{Relaxometry Results}

The relaxometry results are presented in the Figure 5. The acid mixture (AM sample) showed a straight line parallel to the frequency axis, being $\mathrm{T}_{1} \mathrm{H}$ quasi constant for all frequencies. For octadecylamine, the variation of relaxation time versus frequency presented a sigmoidal curve (S shape). For the graphite modified with acid mixture (AM-G sample), the curve revealed a rise from $10^{5} \mathrm{~Hz}$ to $10^{7} \mathrm{~Hz}$, after which it remained constant. The profile was due to the presence of carboxyl and hydroxyl groups inside the graphite galleries, which can be chemically linked or adsorbed on the surface. The relaxometry curve of graphite modified with octadecylamine (ODA-AM-G) also showed that the relaxation time was dependent on the frequency. The profile of the graphite/ octadecylamine curve indicated two rises. The first started at $10^{5} \mathrm{~Hz}$ and finished at approximately $10^{6} \mathrm{~Hz}$. There was a plateau between $10^{6}-10^{7} \mathrm{~Hz}$ but the point near $10^{9}$ $\mathrm{Hz}$ suggested that a second rise occurred. It could be assumed that at least two kinds of structures were present in the graphite/octadecylamine sample. The first rise could represent the exfoliated structure where the octadecylamine molecules are less constricted while the second one could be attributed to the delaminated structure-octadecylamine molecules are more squeezed between the graphite layers. The result supports the obser vations from the WAXD and TG analyses.

\section{Conclusion}

Natural graphite was modified by the action of an acid mixture. The presence of hydroxyl and carboxyl groups on the graphite lamellar surface allowed its chemical modification through reaction with octadecylamine. Organically modified graphite was obtained. The techniques of characterization allowed inferring that a mix of structures—delaminated and exfoliated — was achieved.

\section{Acknowledgements}

We would like to thank the Brazilian research agencies CNPq and CAPES for financial support, CETEM-Brasil for assisting with the SEM analysis and also Laboratório de Engenharia Química e Biologia and Laboratório de 


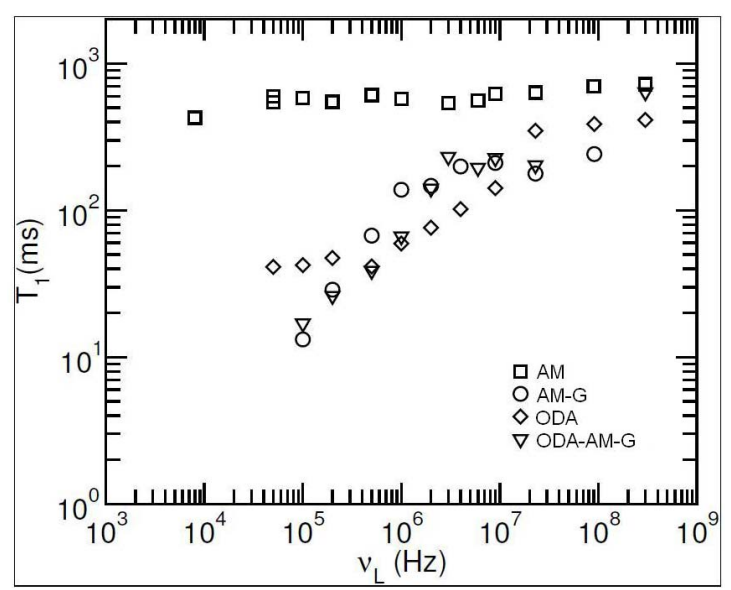

Figure 5. LFNMR for AM, AM-G, ODA-AM-G and ODA samples.

Ressonância Magnética Nuclear, both of IST in Portugal, for helping with part of this study.

\section{REFERENCES}

[1] M. S. S. B. Monteiro, R. P. C. Neto, I. C. S. Santos, E. O. da Silva and M. I. B. Tavares, "Inorganic-Organic Hybrids Based on Poly( $\varepsilon$ - Caprolactone) and Silica Oxide and Characterization by Relaxometry Appling Low-Field NMR," Materials Research, Vol. 15, No. 6, 2012, pp. 825832. doi:10.1590/S1516-14392012005000121

[2] P. R. Pinto, L. C. Mendes, M. L. Dias and C. Azuma, "Synthesis of Acryle-Modified Sol-Gel Silica," Colloid and Polymer Science, Vol. 284, No. 5, 2006, pp. 529-535. doi:10.1007/s00396-005-1424-0

[3] M. I. B. Tavares, P. S. R. C. da Silva, E. O. da Silva, C. Legramanti, A. A. Passos and R. P. C. Neto, "The Evaluation of Polymeric Composites from Nuclear Magnetic Resonance Relaxometry," The 6th International Conference on Quantum, Nano and Micro Technologies, ICQNM, Rome, 19-24 August 2012, pp. 52-55.

[4] L. M. Brito and M. I. Tavares, “ Evaluation of the InfluEnce of Nanoparticles' Shapes on the Formation of Poly (Lactic Acid) Nanocomposites Obtained Employing the Solution Method," Journal of Nanoscience and Nanotechnology, Vol. 12, No. 16, 2012, pp. 4508-4513. doi:10.1166/jnn.2012.6176

[5] L. C. Mendes, D. F. Silva and A. S. Lino, "Linear LowDensity Poliethylene and $\alpha$-Zirconium Phosphate Nanocomposites: Evidence from Thermal, Thermo-Mechanical, Morphological and Low-Field Nuclear Magnetic Resonance Techniques," Journal of Nanoscience and Nanotechnology, Vol. 12, No. 12, 2012, pp. 8867-8873. doi:10.1166/jnn.2012.6718

[6] Y. Yang, C. Liu and H. Wu, "Preparation and Properties Of Poly(Vinyl Alcohol)/Exfoliated $\alpha$ Zirconium Phosphate Nanocomposites Films," Polymer Testing, Vol. 28, No. 4, 2009, pp. 371-377. doi:10.1016/j.polymertesting.2008.12.008

[7] D.-Y. Wang, X.-Q. Liu, J.-S. Wang, Y.-Z. Wang, A. A.
Stec and T. R. Hull, "Preparation and Characterization of a Novel Fire Retardant PET/ $\alpha$-Zirconium Phosphate Nanocomposite," Polymer Degradation and Stability, Vol. 93, No. 5, 2008, pp. 1024-1030.

doi:10.1016/i.polymdegradstab.2007.12.011

[8] L. S. Brandão, L. C. Mendes, M. E. Medeiros, L. Sirelli and M. L. Dias, "Thermal and Mechanical Properties of Poly(Ethylene Terephthalate)/Lamellar Zirconium Phosphate Nanocomposites," Journal of Aplied Polymer Science, Vol. 102, No. 4, 2006, pp. 3868-3876. doi:10.1002/app.24096

[9] R. Sengupta, M. Bhattacharya and S. Bandyopadhyay, "A Review on the Mechanical and Electrical Properties of Graphite and Modified Graphite Reinforced Polymer Composites," Progress in Polymer Science, Vol. 36, No. 5, 2011, pp. 638-670. doi:10.1016/j.progpolymsci.2010.11.003

[10] Y. L. Hsin, K. C. Hwang and C. T. Yeh, "Poly(Vinylpyrrolidone)-Modified Graphite Carbon Nanofibers as Promising Supports for PtRu Catalysts in Direct Methanol Fuel Cells," Journal of american Chemical Society, Vol. 19, No. 32, 2007, pp. 9999-10010. doi:10.1021/ja072367a

[11] D. K. Resende, C. B. Dornelas, M. I. B. Tavares, A. S. Gomes, L. A. Moreira, L. M. Cabral and L. A. Simeoni, "Preparação de Argila Modificada com Cloreto de Cetilpiridíneo e Avaliação da Interação desta com o PVC," Polímeros, Vol. 30, No. 3, 2011, pp. 1379-1382.

[12] Z. González, A. Sanchez, C. Blanco, M. Granda, R. Menédez and R. Santamaría, "Enhanced Performance of a Bi-Modified Graphite Feltas the Positive Electrode of a Vanadium Redox Flow Battery," Electrochemistry Communications, Vol. 13, No. 12, 2011, pp. 1379-1382. doi:10.1016/j.elecom.2011.08.017

[13] M. Mallesha, R. Manjunatha, C. Nethravathi, G. S. Suresh, M. Rajamathi, J. S. Melo, T. V. Venkatesha, "Functinalizatized-Graphene Modified Graphite Electrode for the Selective Determination of Dopamine in Presence of Uric Acid and Ascorbic Acid," Bioelectrochemistry, Vol. 81, No. 2, 2011, pp. 104-108. doi:10.1016/j.bioelechem.2011.03.004

[14] E. Zacco, M. I. Pividori, X. Llopis, M. Del Valle and S. A. Alegret, "Renewable Protein A Modified Graphite-Epoxy Composite for Electrode Mical Immunosensing," Journal of Immunological Methods, Vol. 286, No. 1-2, 2004, pp. 35-46. doi:10.1016/j.jim.2003.11.014

[15] A. Malas and C. K. Das, "Development of Modified Expanded Graphite-Filled Solution Polymerized StyreneButadiene Rubber Vulcanizates in the Presence and Absence of Carbon Black," Polymer Engineering and Science, Vol. 53, No. 2, 2013, pp. 1-9.

[16] E. R. de sousa, E. P. Marques, E. N. Fernandes, J. Zhang and A. L. B. Marques, "Graphite Electrodes Modified by 8-Hydroxyquinolines and Its Application for the Determination of Copper in Trace Levels," Journal of the Brazilian Chemical Society, Vol. 17, No. 1, 2006, pp. 177-183. doi:10.1590/S0103-50532006000100025

[17] M.-H. Chen, T.-Y. Lin and T.-C. Chou, "Trichloroethylene Sensor by Using Electrodeposited Pb-Modified Graphite Strip Electrode," Journal of the Electrochemical 
Society, Vol. 149, No. 3, 2002, pp. 487-492. doi:10.1149/1.1449955

[18] Y.-X. Pan, Z.-Z. Yu, Y.-C. Ou and G.-H. Hu, “A New Process of Fabricating Electrically Conducting Nylon 6/Graphite Nanocomposites via Intercalation Polymerization," Journal of Polymer Science Part B: Polymer Physics, Vol. 38, No. 12, 2000, pp. 1626-1633. doi:10.1002/(SICI)1099-0488(20000615)38:12<1626::AI D-POLB80>3.0.CO;2-R

[19] F. M. Uhl and C. A. Wilkie, "Polystyrene/graphite Nanocomposites: Effect on Thermal Stability," Polymer Degradation and Stability, Vol. 76, No. 1, 2002, pp. 111-122. doi:10.1016/S0141-3910(02)00003-4

[20] V. Panwar, B. Kang, J.-O. Park, S. Park and R. M. Mehra, "Study of Dielectric Properties of Styrene Acrylonitrile
Graphite Sheets Composites in Low and High Frequency Region," European Polymer Journal, Vol. 45, 2009, pp. 1777-1784. doi:10.1016/i.eurpolymj.2009.02.020

[21] D. M. Sousa, G. D. Marques, J. M. Cascais and P. J. Sebastião, "Desktop Fast-Field Cycling Nuclear Magnetic Resonance Relaxometer," Solid State Nuclear Magnetic renance, Vol. 38, No. 1, 2010, pp. 36-43. doi:10.1016/i.ssnmr.2010.07.001

[22] M. S. M. Preto, M. I. B. Tavares, P. J. Sebastião and R. B. V. Azeredo, "Determination of Herbal Authenticity by Low-Field NMR," Food Chemistry, Vol. 136, No. 3-4, 2013, pp. 1272-1276. doi:10.1016/j.foodchem.2012.09.045 